\title{
Effect of Coagulant-Flocculant Reagents on Aerobic Granular Biomass
}

Ángeles Val del Río *, Nicolás Morales, Mónica Figueroa, Anuska Mosquera-Corral, José Luis Campos and Ramón Méndez

Department of Chemical Engineering, School of Engineering, University of Santiago de Compostela. E-15782. Santiago de Compostela, Spain. (E-mail: mangeles.val@usc.es; nicolas.morales@usc.es; monica.figueroa@usc.es; anuska.mosquera@usc.es; joseluis.campos@usc.es; ramon.mendez.pampin@usc.es).

*Corresponding author: Department of Chemical Engineering, School of Engineering, University of Santiago de Compostela. E-15782. Santiago de Compostela, Spain. Telephone: 0034881816739, Fax: 0034881816702. E-mail: mangeles.val@usc.es.

\begin{abstract}
BACKGROUND: Technologies based on aerobic granular biomass are presented as a new alternative for its application to the wastewater treatment due to its advantages in comparison with the conventional activated sludge ones. However the properties of the aerobic granules can be influenced by the presence of residual amounts of coagulantflocculant reagents, frequently used as pre-treatment before the biological process. In this work the effect of these compounds on aerobic granular biomass development was tested.
\end{abstract}

RESULTS: The presence of coagulant-flocculant reagents led to a worse biomass retention capacity with a lower VSS concentration compared to a control reactor (4.5 vs. $7.9 \mathrm{~g} \mathrm{VSS} / \mathrm{L}$ ) and with a higher SVI (70 vs. $40 \mathrm{~mL} / \mathrm{g}$ TSS) and diameter (5.0 vs. 2.3 
$\mathrm{mm})$. These reagents also caused a decrease in the maximum oxygen consumption rate, but the removal efficiencies of organic matter (90\%) and nitrogen $(60 \%)$ achieved were similar than the control reactor.

CONCLUSION: The continuous presence of residual levels of coagulant-flocculant reagents from the pre-treatment unit negatively affected the formation process and the physical properties of the aerobic granules, however the removal of organic matter and nitrogen were not affected.

Keywords: aerobic granule; coagulant; flocculant; SOUR; organic matter; nitrogen.

\section{INTRODUCTION}

Technologies based on aerobic granular sludge appear as a promising option for their application to the wastewater treatment ${ }^{1,2}$. Advantages in comparison to the conventional activated sludge systems rely on the capacity to treat higher loads, to achieve better removal efficiencies, to carry out simultaneous elimination of organic matter, nitrogen and phosphorus ${ }^{3}$, and to produce biomass with better settleability properties and low sludge production. Despite all the advantages of the aerobic granulation the development of this technology is still recent and the research at laboratory scale was focused in the establishment of the optimal operational parameters such as the use of sequencing batch reactors (SBRs), feeding strategy (feast/famine regime), reactor design (large high/diameter ratio), low settling time, aeration intensity (high hydrodynamic shear force), control of the dissolved oxygen concentration, type of substrate, etc. In this sense the study of different types of substrates is important to determine the usefulness of aerobic granulation. Many works have been performed with synthetic ${ }^{3-5}$ and industrial wastewater ${ }^{6-10}$. The effect of different types of toxic 
compounds, like phenol and pyridine as well as the presence of heavy metals and dyes have also been tested ${ }^{11,12}$. However the presence of coagulant-flocculant reagents, commonly employed in the wastewater treatment plants (WWTPs), has not been studied so far.

During the wastewater treatment the use of a pre-treatment before the biological process involving the addition of reagents such as coagulants and flocculants is very common to separate fats and solids. A residual amount of these reagents remains in the supernatant and goes to the biological treatment process, affecting its performance. The presence of coagulant-flocculant reagents in activated sludge systems can avoid the formation of biological foam and the proliferation of filamentous micro-organisms ${ }^{13}$, improve the sludge settling properties ${ }^{14}$ and protect membranes from fouling ${ }^{15}$, but can also have negative effects on the biomass activity ${ }^{14,16}$.

Although there are not specific studies about the effect of these reagents on the formation and properties of the aerobic granular biomass, some studies with cations, such as $\mathrm{Ca}^{+217}$ and $\mathrm{Mg}^{+218}$, show that their presence favour the formation of aerobic granular biomass due to the fact that they act as a bridge to bind negatively charged groups present on bacterial surface and/or extracellular polysaccharides molecules to adhere individual bacteria to each other ${ }^{19}$. So the residual levels of coagulant-flocculant reagents (normally cationic salts) could initially promote the aggregation of the biomass, but the long time effect is not known.

For this reason, the objective of this work was to study the effect of a residual concentration of coagulant-flocculant reagents on an aerobic granular system, with special attention to the formation and the evolution of physical properties of the biomass as well as the removal efficiencies of organic matter and nitrogen. 


\section{EXPERIMENTAL}

\section{Materials}

Two sequencing batch reactors (SBRs) with a total volume of $2.7 \mathrm{~L}$ and a working volume of $1.8 \mathrm{~L}$ were operated at room temperature $\left(18 \pm 1^{\circ} \mathrm{C}\right)$. Dimensions of the units were: height of $480 \mathrm{~mm}$ and inner diameter of $85 \mathrm{~mm}$. The agitation was achieved by aeration through an air diffuser. Two peristaltic pumps were used to add the feeding and discharge the effluent. The exchange volume was fixed at 50\%. Both SBRs were operated in cycles of 3 hours which were distributed as follow: 3 minutes of feeding, 171 minutes of aeration, 1 minute of settling and 5 minutes of effluent withdrawal. A programmable logic controller (PLC) controlled the different phases of operation of the cycles. Both reactors were fed with a synthetic medium with the following composition: $\mathrm{NaAc} \cdot 3 \mathrm{H}_{2} \mathrm{O} 1.7 \mathrm{~g} / \mathrm{L}, \mathrm{NH}_{4} \mathrm{Cl} 0.3 \mathrm{~g} / \mathrm{L}, \mathrm{K}_{2} \mathrm{HPO}_{4} 0.12 \mathrm{~g} / \mathrm{L}, \mathrm{MgSO}_{4} 0.04 \mathrm{~g} / \mathrm{L}, \mathrm{CaCl}_{2} \cdot 2 \mathrm{H}_{2} \mathrm{O}$ $0.07 \mathrm{~g} / \mathrm{L}, \mathrm{KCl} 0.02 \mathrm{~g} / \mathrm{L}$ and $1 \mathrm{~mL} / \mathrm{L}$ of a trace solution according to Smolders et al. ${ }^{20}$. One reactor was used as "control" and the other one, "CF", was supplemented with coagulant $(2.5 \mathrm{mg} / \mathrm{L}$ of Polychloride of aluminium) and flocculant $(1.5 \mathrm{mg} / \mathrm{L}$ of commercial polyelectrolyte Chemifloc ${ }^{\circledR}$ ) according to the range of values of the residual concentrations in the primary settled wastewater ${ }^{14}$.

The reactors were operated along 135 days maintaining the same conditions (feeding and operation) to ensure a sufficient operational period to study the possible different behaviour of both systems.

\section{Analytical methods}

Concentrations of soluble chemical oxygen demand (CODs), ammonia, nitrite, nitrate, dissolved oxygen (DO), volatile suspended solids (VSS) and sludge volumetric index (SVI) were determined according to the Standard Methods ${ }^{21}$. The morphology and size 
distribution of the granules were measured regularly by using an Image Analysis procedure with a stereomicroscope (Stemi 2000-C, Zeiss) according to Tijhuis et al. ${ }^{22}$. Biomass density $\left(\rho_{b}\right)$ in terms of g VSS per litre of granules, was determined with dextran blue following the methodology proposed by Beun et al. ${ }^{4}$.

\section{Calculations}

The maximum specific oxygen consumption rate $\left(\mathrm{r}_{\max }\right)$ in $\mathrm{g} \mathrm{O}_{2} / \mathrm{g}$ VSS $\cdot \mathrm{d}$ was calculated from the specific oxygen uptake rate (SOUR) value considering that under the operational conditions the reaction obeys a zero-order rate limited by internal diffusion (equation 1$)^{23}$ :

$\mathrm{SOUR}=\left[1-\left[\frac{1}{2}+\operatorname{sen}\left[\frac{1}{3} \operatorname{arctg}\left(\frac{3 \cdot\left(\frac{\mathrm{R}_{\mathrm{p}}}{3 \cdot \sqrt{2}} \cdot \sqrt{\frac{\mathrm{r}_{\max } \cdot \rho_{\mathrm{b}}}{\mathrm{D}_{\mathrm{O} 2} \cdot \mathrm{C}_{\mathrm{O} 2}}}\right)^{2}}{2 \cdot \sqrt{3 \cdot\left(\frac{\mathrm{R}_{\mathrm{p}}}{3 \cdot \sqrt{2}} \cdot \sqrt{\frac{\mathrm{r}_{\max } \cdot \rho_{\mathrm{b}}}{\mathrm{D}_{\mathrm{O} 2} \cdot \mathrm{C}_{\mathrm{O} 2}}}\right)^{2}}-1}\right]\right]\right]\right]^{\max }$

Where $R_{p}$ is the particle radius $(d m) ; D_{O 2}$ is the diffusion coefficient of oxygen $\left(\mathrm{dm}^{2} / d\right)$; $\rho_{\mathrm{b}}$ is the biomass density ( $\mathrm{g} \mathrm{VSS} / \mathrm{L}_{\text {granule }}$ ) and $\mathrm{C}_{\mathrm{O} 2}$ is the oxygen concentration in the bulk liquid $\left(\mathrm{g} \mathrm{O}_{2} / \mathrm{L}\right)$.

The SOUR ( $\mathrm{g} \mathrm{O}_{2} / \mathrm{g}$ VSS·d) was calculated using the equation (2):

$\operatorname{SOUR}=\frac{\mathrm{k}_{\mathrm{La}} \cdot\left(\mathrm{O}_{2}{ }^{*}-\mathrm{O}_{2}\right)}{\mathrm{X}}$

Where $\mathrm{k}_{\mathrm{La}}$ is the mass transfer coefficient $\left(\mathrm{d}^{-1}\right) ; \mathrm{O}_{2}{ }^{*}$ is the oxygen saturation concentration for the system $\left(\mathrm{g} \mathrm{O}_{2} / \mathrm{L}\right) ; \mathrm{O}_{2}$ the oxygen concentration level during the feast period ( $\mathrm{g} \mathrm{O}_{2} / \mathrm{L}$ ) and $\mathrm{X}$ is the biomass concentration inside the reactor ( $\mathrm{g} \mathrm{VSS} / \mathrm{L}$ ). 


\section{RESULTS AND DISCUSSION}

\section{Formation and characteristics of the aerobic granular biomass}

The reactors ( $\mathrm{CF}$ and control) were inoculated with $0.5 \mathrm{~L}$ of an activated sludge from an urban WWTP with a SVI around $200 \mathrm{~mL} / \mathrm{g}$ TSS and a solids concentration of $5 \mathrm{~g}$ VSS/L. To avoid the excessive solids wash out, the first 8 days of operation the settling time was maintained at 2 minutes which supposed that only the particles with a settling velocity higher than $5 \mathrm{~m} / \mathrm{h}$ were retained inside the reactors. Then the settling time was changed to 1 minute to promote a complete washout of flocculent biomass with a settling velocity lower than $10 \mathrm{~m} / \mathrm{h}$. After 10 days of operation the formation of the first aggregates could be appreciated in both systems (Fig. 1.a).

Initially the SVI of the biomass in the control reactor decreased from 192 to around 40 $\mathrm{mL} / \mathrm{g}$ TSS (day 63) but on day 70 the SVI value increased up to $130 \mathrm{~mL} / \mathrm{g}$ TSS due to clogging of the air diffuser (Fig. 2.a1). Once it was cleaned the SVI started to gradually decrease down to $40 \mathrm{~mL} / \mathrm{g}$ TSS. In the CF reactor the SVI values ranged between 120 and $70 \mathrm{~mL} / \mathrm{g}$ TSS (Fig. 2.a2), being at the end of the operation higher than on the control.

The evolution of the average particle size of the granules was different in both reactors (Fig. 2.a). After the first 20 days of operation, in the control reactor the granules had an average diameter of $4.7 \mathrm{~mm}$ which remained almost constant until day 70 . Then, when the clogging of the air diffuser was solved, it gradually decreased down to $2.3 \mathrm{~mm}$ (day 135). In the CF reactor the particles diameter progressively increased from $2.6 \mathrm{~mm}$ (day 23) to $5.0 \mathrm{~mm}$ (day 135), despite that the air diffuser also was cleaned to have the same conditions than on the control reactor. This increase in the size of the aggregates could be due to the presence of a residual amount of cations from the coagulant reagent, since previous works show that the addition of cations to obtain aerobic granular biomass 
produces granules with bigger diameter ${ }^{18}$. Guo et al. ${ }^{24}$ also observed an increase in the particle size of the sludge flocs in a membrane bioreactor with the addition of three different flocculants. At the final period of the operation the granules aspect was very different in both systems. Granules from the control were smaller and with smoother surfaces than those from CF reactor (Fig. 1.b).

The biomass concentration inside both reactors was quite similar until day 80 of operation with values between 0.9-2.6 $\mathrm{g}$ VSS/L for control and 0.7-3.7 $\mathrm{g}$ VSS/L for CF (Fig. 2.b). Then on the control reactor the biomass concentration started to increase up to values of $7.9 \mathrm{~g} \mathrm{VSS} / \mathrm{L}$ at the end of the operational period, while on $\mathrm{CF}$ reactor the biomass concentration reached a maximum value of $4.5 \mathrm{~g} \mathrm{VSS} / \mathrm{L}$ and then it decreased to a value around $3 \mathrm{~g} \mathrm{VSS} / \mathrm{L}$ at the end of the operation. During the first 80 days the average solids concentration in the effluent was of $0.14 \mathrm{~g} \mathrm{VSS} / \mathrm{L}$ in both reactors and the solid retention time (SRT) ranged between 2 and 6 days (Fig. 2.b). Nevertheless, from day 80 the average solids concentration in the effluent of the control reactor decreased down to $0.11 \mathrm{~g} \mathrm{VSS} / \mathrm{L}$ while in the $\mathrm{CF}$ reactor it increased up to $0.18 \mathrm{~g}$ VSS/L. The better biomass retention in the control compared to the CF reactor would explain the different values of biomass concentration obtained at the end of the operational period. In both systems the biomass yield coefficient was around $0.28 \mathrm{~g}$

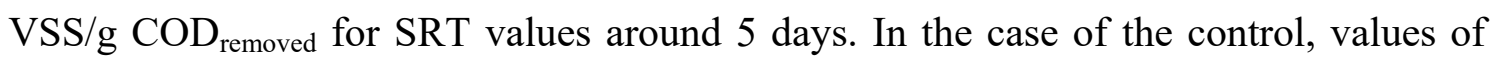
$0.24 \mathrm{~g} \mathrm{VSS} / \mathrm{g} \mathrm{COD}_{\text {removed }}$ were observed for SRT values around 18 days (days 100-140 of operation).

The food-to-microorganism $(\mathrm{F} / \mathrm{M})$ ratio on the control reactor before day 80 was maintained in values over or around $1 \mathrm{~g} \mathrm{COD}_{\mathrm{s}} / \mathrm{g} \mathrm{VSS} \cdot \mathrm{d}$ (Fig. 2.a1). From this day, due to the biomass accumulation, the $\mathrm{F} / \mathrm{M}$ ratio progressively decreased to $0.3 \mathrm{~g} \mathrm{COD}_{\mathrm{s}} / \mathrm{g}$ VSS $d$ at the end of the operational period. This operational period with values of the 
$\mathrm{F} / \mathrm{M}$ ratio lower than $1 \mathrm{~g} \mathrm{COD}_{\mathrm{s}} / \mathrm{g} \mathrm{VSS} \cdot \mathrm{d}$ corresponded with the improvement in the aerobic granules characteristics (decrease in the SVI and average diameter). However on the $\mathrm{CF}$ reactor the $\mathrm{F} / \mathrm{M}$ ratio was around $1 \mathrm{~g} \mathrm{COD}_{\mathrm{s}} / \mathrm{g} \mathrm{VSS} \cdot \mathrm{d}$ from day 20 until the end of the operation (Fig. 2.a2). These results are in accordance with other authors who observed that when the $\mathrm{F} / \mathrm{M}$ ratio was over $1 \mathrm{~g} \mathrm{COD} / \mathrm{g} \mathrm{VSS} \cdot \mathrm{d}$ the aggregates presented worse settling properties, being the adequate ratio for aerobic granulation around $0.5 \mathrm{~g}$ $\mathrm{COD} / \mathrm{g}$ VSS $\cdot \mathrm{d}^{25,26}$.

The profile of the COD concentration during an operational cycle was determined several times during the whole time of operation to determine the length of the feast period (presence of substrate in the liquid phase as $\mathrm{COD}_{\mathrm{S}}$ ) and the famine period (absence of $\mathrm{COD}_{\mathrm{S}}$ in the liquid media). The Famine/Feast ratio for each reactor was calculated for the different measured cycles and represented in Fig. 3.a. During the whole operation this ratio was higher for control than for $\mathrm{CF}$, although this difference was more significant from day 80 of operation that coincides with the higher concentration of biomass inside the control in comparison with CF (Fig. 2.b). At the end of the operation time the value of this ratio was of 7.6 for control and 3.5 for CF. Mosquera-Corral et al. ${ }^{27}$ working with a SBR using a similar cycle distribution checked the effect of the dissolved oxygen concentration on the Famine/Feast ratio and observed that compact and dense granules were obtained when this ratio had values between 7.5 and 10. De Kreuk and van Loosdrecht ${ }^{28}$ also observed that a long feast phase caused a filamentous outgrowth and granule instability. In this work the presence of coagulantflocculant reagents decreased the Famine/Feast ratio in comparison with the control reactor. This fact could be related to the presence of filamentous microorganisms in the granules surface of CF reactor (Fig. 1.b2) and the high average diameter of the aggregates and SVI value (Fig. 2.a2). 
The SOUR of both reactors was periodically tested during the operational cycle to determine the impact of the coagulant-flocculant reagents on microbial activity. Since the reaction is limited by internal diffusion, the maximum specific oxygen consumption rate $\left(r_{\max }\right)$ was calculated according to equation (1) in order to avoid the effects of particle size and oxygen concentration on the specific activity value obtained. For similar SRT values, the maximum specific oxygen consumption rate observed in the control reactor was higher than that observed in CF reactor (Fig. 3.b) which indicates that the presence of coagulant-flocculant reagents decreases the activity of the aerobic granular biomass. A similar behaviour was obtained by Lees et al. ${ }^{14}$ who checked the effect of three different coagulants with different residual ion concentrations on an activated sludge and observed a decrease in the SOUR in the $87 \%$ of the cases. Working with aerobic granular biomass Ren et al. ${ }^{29}$ observed that the SOUR decreased from 27 to $10 \mathrm{mg} \mathrm{O} / \mathrm{g} \mathrm{VSS} \cdot \mathrm{h}$ when the concentration of $\mathrm{Ca}^{+2}$ in the feeding increased from 20 to $40 \mathrm{mg} / \mathrm{L}$, suggesting that the $\mathrm{Ca}^{+2}$ accumulation inside the granules might have a negative effect on their bioactivity. Luo et al. ${ }^{30}$ studied the effect of a trace amount of coagulant (polyacrylamide) on long-term performance of activated sludge and found that the optimal dosage to improve the SOUR was $0.1 \mathrm{mg} / \mathrm{L}$, but for higher concentrations the SOUR started to decrease. Dapena-Mora et al. ${ }^{16}$ with Anammox biomass observed a decrease of around $30 \%$ in the maximum specific activity when a flocculant concentration of $1 \mathrm{mg} / \mathrm{L}$ was applied to the system. Therefore the presence of these compounds in a continuous aerobic system seems to decrease the biological activity when their concentration exceeds a certain value. An explanation for this could be the adsorption of the coagulant-flocculant compounds onto the surface of the biomass as a result of the electrostatic interaction between a positively charged group of 
the reagents with the negatively charged surface of the microorganisms, reducing the active surface of the biomass and consequently its bioactivity.

In the case of the control, the maximum specific oxygen consumption rate decreased from 6.0 to $2.3 \mathrm{~g} \mathrm{O}_{2} /(\mathrm{g} \mathrm{VSS} \cdot \mathrm{d})$ with the increase in the SRT from 2.5 to $18 \mathrm{~d}$. Ouyang and Liu ${ }^{31}$ also observed that the bioactivity and the SOUR decreased with the increase in the SRT in a membrane bioreactor. Han et al. ${ }^{32}$ attributed this decrease to the specific biological activity at prolonged SRT by the accumulation of inert biomass due to endogenous respiration.

\section{Organic matter and nitrogen removal}

Since the addition of the coagulant-flocculant reagents did not suppose a significant increase in its organic matter content, the organic loading rates (OLRs) applied to both reactors were similar and ranged between 2 and $3 \mathrm{~kg} \mathrm{COD} /\left(\mathrm{m}^{3} \cdot \mathrm{d}\right)$. The presence of a residual amount of coagulant-flocculant reagents did not affect the organic matter removal efficiency since it was over $90 \%$ during the whole operational time for both reactors (Fig. 4).

The nitrogen loading rate (NLR) fed to the SBRs varied between 0.2 and $0.3 \mathrm{~kg} \mathrm{~N}$ $\mathrm{NH}_{4}^{+} /\left(\mathrm{m}^{3} \cdot \mathrm{d}\right)$. The efficiency of the nitrification process fluctuated in both systems and a stable and high value was achieved only for the control at the end of the operational period (Fig. 4.a) when high biomass concentration was reached.

The nitrification efficiency was closely related to the SRT of the systems and it was observed that efficiency close to $100 \%$ was obtained only when the reactors operated at SRT values higher than 5 days (Fig. 5.a). Therefore, the better stability of the nitrification process observed for the control can be attributed to its higher biomass retention capacity. The maximum nitrogen removal achieved was around $60 \%$ in both 
systems (Fig. 4). Fig. 5.b shows a correlation between nitrification and nitrogen removal efficiencies up to values around $60 \%$. This fact indicates that the nitrification is the limiting step of nitrogen removal when its efficiency was lower than this value. Higher efficiencies of nitrification did not improve the nitrogen removal efficiency since in that case the volume exchange ratio applied would be the limiting factor. For both systems the volume exchange ratio applied was of $50 \%$ and, theoretically, a maximum nitrogen removal efficiency of $50 \%$ could be expected. The higher value obtained is probably due to the consumption of ammonia for the biomass growth.

\section{CONCLUSIONS}

The aerobic granular reactor operated in the presence of trace amounts of coagulantflocculant reagents had a lower biomass retention capacity compared to the control system due to the worse physical properties of the granules obtained. These granules presented a fluffy and filamentous aspect which corresponded to the operational periods with low values of the Famine/Feast ratio observed.

The maximum specific oxygen consumption rate $\left(r_{\max }\right)$ of the aerobic granules with coagulant-flocculant reagents was lower than the control, which indicates that the presence of these compounds decreases the activity of the biomass.

In both reactors, the maximum removal efficiencies of organic matter and nitrogen achieved were similar, being around $90 \%$ and $60 \%$, respectively. However, the operational stability of the reactor with the presence of coagulant-flocculant reagents was worse due to the low SRT obtained. 


\section{Acknowledgements}

This work was funded by the Spanish Government (TOGRANSYS CTQ2008-06792C02-01, NOVEDAR_Consolider CSD2007-00055) and Ministry of Education of Spain (FPU AP2006-01478).

\section{References}

1. de Bruin LMM, de Kreuk MK, van der Roest HFR, Uijterlinde $C$ and van Loosdrecht MCM, Aerobic granular sludge technology: an alternative to activated sludge? Water Sci and Technol 49:1-7 (2004).

2. Liu Y and Tay J-H, State of the art of biogranulation technology for wastewater treatment. Biotechnol Adv 22:533-563 (2004).

3. de Kreuk MK, Heijnen JJ and van Loosdrecht MCM, Simultaneous COD, nitrogen, and phosphate removal by aerobic granular sludge. Biotechnol Bioeng 90:761769 (2005).

4. Beun JJ, Hendriks A, van Loosdrecht MCM, Morgenroth E, Wilderer PA and Heijnen JJ, Aerobic granulation in a sequencing batch reactor. Water Res 33:2283-2290 (1999).

5. Tay JH, Liu QS and Liu Y, Aerobic granulation in sequential sludge blanket reactor. Water Sci and Technol 46:13-18 (2002).

6. Arrojo B, Mosquera-Corral A, Garrido JM and Méndez R, Aerobic granulation with industrial wastewater in sequencing batch reactors. Water Res 38:33893399 (2004).

7. Cassidy DP and Belia E, Nitrogen and phosphorus removal from an abattoir wastewater in a SBR with aerobic granular sludge. Water Res 39:4817-4823 (2005).

8. Figueroa M, Mosquera-Corral A, Campos JL and Mendez R, Treatment of saline wastewater in SBR aerobic granular reactors. Water Sci and Technol 58:479485 (2008).

9. Inizan M, Freval A, Cigana $\mathrm{J}$ and Meinhold $\mathrm{J}$, Aerobic granulation in a sequencing batch reactor (SBR) for industrial wastewater treatment. Water Sci and Technol 52:335-343 (2005). 
10. Schwarzenbeck N, Erley R, Mc Swain BS, Wilderer PA and Irvine RL, Treatment of malting wastewater in a granular sludge sequencing batch reactor (SBR). Acta Hydroch Hydrob 32:16-24 (2004).

11. Moussavi G, Barikbin B and Mahmoudi M, The removal of high concentrations of phenol from saline wastewater using aerobic granular SBR. Chem Eng $J$ 158:498-504 (2010).

12. Adav SS, Lee DJ, Show KY and Tay JH, Aerobic granular sludge: Recent advances. Biotechnol Adv 26:411-423 (2008).

13. Lansky M, Ruzickova I, Benkakova A and Wanner J, Effect of coagulant dosing on physicochemical and microbiological characteristics of activated sludge and foam formation. Acta Hydroch Hydrob 33:266-269 (2005).

14. Lees EJ, Noble B, Hewitt R and Parsons SA, The impact of residual coagulant on the respiration rate and sludge characteristics of an activated microbial biomass. Process Saf Environ 79:283-290 (2001).

15. Pendashteh AR, Fakhru'l-Razi A, Madaeni SS, Abdullah LC, Abidin ZZ and Biak DRA, Membrane foulants characterization in a membrane bioreactor (MBR) treating hypersaline oily wastewater. Chem Eng J 168:140-150 (2011).

16. Dapena-Mora A, Fernandez I, Campos JL, Mosquera-Corral A, Mendez R and Jetten MSM, Evaluation of activity and inhibition effects on Anammox process by batch tests based on the nitrogen gas production. Enzyme Microb Tech 40:859-865 (2007).

17. Jiang HL, Tay JH, Liu Y and Tay STL, Ca2+ augmentation for enhancement of aerobically grown microbial granules in sludge blanket reactors. Biotechnol Lett 25:95-99 (2003).

18. Li XM, Liu QQ, Yang Q, Guo L, Zeng GM, Hu JM and Zheng W, Enhanced aerobic sludge granulation in sequencing batch reactor by $\mathrm{Mg} 2+$ augmentation. Bioresource Technol 100:64-67 (2009).

19. Campos JL, Figueroa M, Mosquera-Corral A and Mendez R, Aerobic sludge granulation: state-of-the-art. Int J Environ Eng 1:136-151 (2009).

20. Smolders GJF, van Loosdrecht MCM and Heijnen JJ, A metabolic model for the biological phosphorus removal process. Water Sci Technol 31:79-93 (1995).

21. APHA-AWWA-WPCF, Standard methods for the examination of water and wastewater. American Public Health Association/American Water Works Association/Water Environment Federation, Washigton DC, USA (2005). 
22. Tijhuis L, Vanloosdrecht MCM and Heijnen JJ, Formation and growth of heterotrophic aerobic biofilms on small suspended particles in airlift reactors. Biotechnol Bioeng 44:595-608 (1994).

23. González Velasco JR, Gónzalez Marcos JA, Gónzalez Marcos MP, Guitérrez Ortiz JI and Guitiérrez Ortiz MA, Applied Chemical Kinetic. Síntesis, Madrid (1999).

24. Guo WS, Ngo HH, Vigneswaran S, Dharmawan F, Nguyen TT and Aryal R, Effect of different flocculants on short-term performance of submerged membrane bioreactor. Sep Purif Technol 70:274-279 (2010).

25. Yang SF, Li XY and Yu HQ, Formation and characterisation of fungal and bacterial granules under different feeding alkalinity and $\mathrm{pH}$ conditions. Process Biochem 43:8-14 (2008).

26. Jungles MK, Figueroa M, Morales N, Val del Río Á, da Costa RHR, Campos JL, Mosquera-Corral A and Méndez R, Start up of a pilot scale aerobic granular reactor for organic matter and nitrogen removal. J Chem Technol Biot 86:763$768(2011)$.

27. Mosquera-Corral A, de Kreuk MK, Heijnen JJ and van Loosdrecht MCM, Effects of oxygen concentration on N-removal in an aerobic granular sludge reactor. Water Res 39:2676-2686 (2005).

28. de Kreuk MK and van Loosdrecht MCM, Selection of slow growing organisms as a means for improving aerobic granular sludge stability. Water Sci Technol 49:917 (2004).

29. Ren TT, Liu L, Sheng GP, Liu XW, Yu HQ, Zhang MC and Zhu JR, Calcium spatial distribution in aerobic granules and its effects on granule structure, strength and bioactivity. Water Res 42:3343-3352 (2008).

30. Luo YL, Yang ZH, Xu ZY, Zhou LJ, Zeng GM, Huang J, Xiao Y and Wang LK, Effect of trace amounts of polyacrylamide (PAM) on long-term performance of activated sludge. J Hazard Mater 189:69-75 (2011).

31. Ouyang K and Liu JX, Effect of sludge retention time on sludge characteristics and membrane fouling of membrane bioreactor. J Environ Sci-China 21:1329-1335 (2009).

32. Han SS, Bae TH, Jang GG and Tak TM, Influence of sludge retention time on membrane fouling and bioactivities in membrane bioreactor system. Process Biochem 40:2393-2400 (2005). 

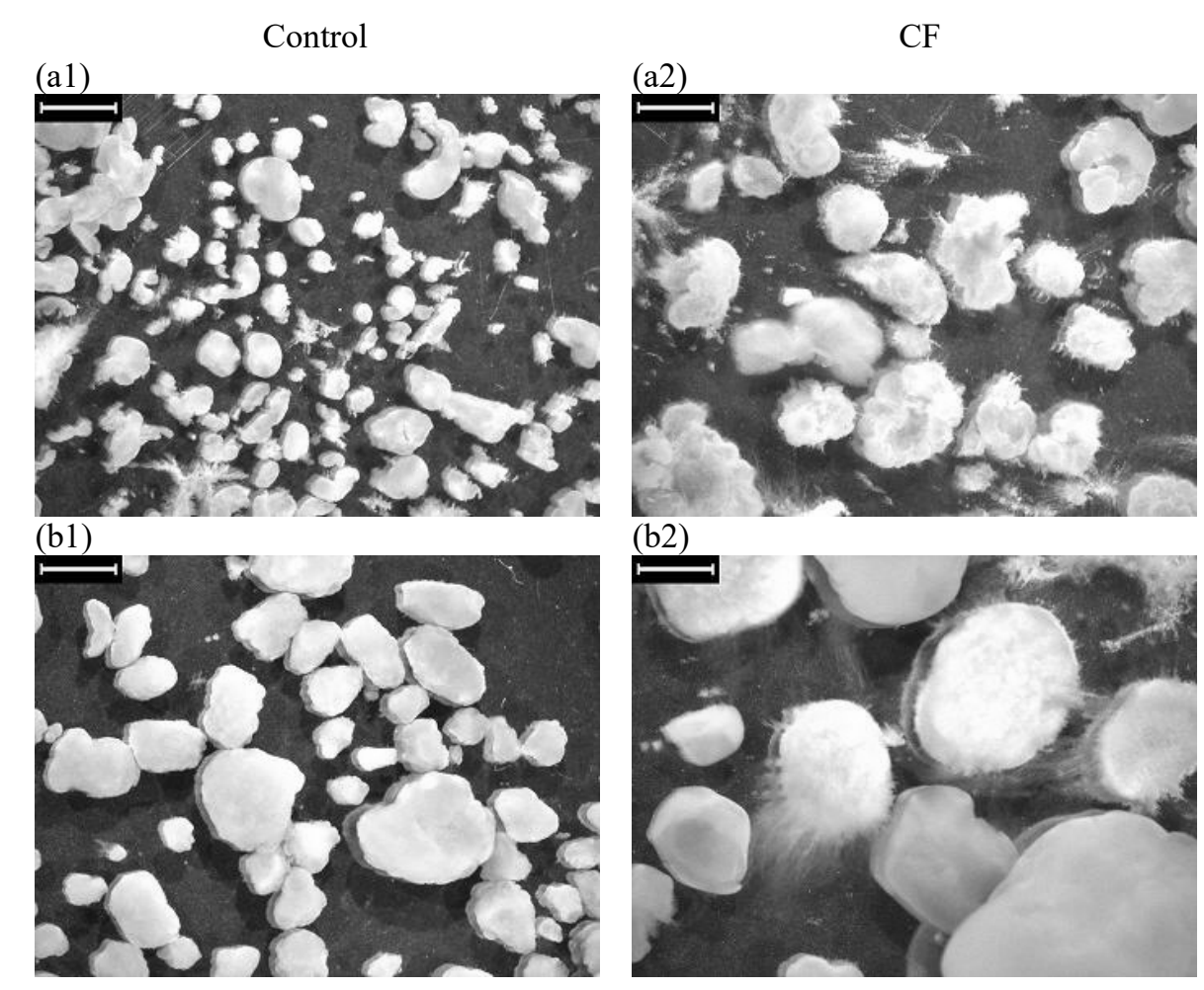

Figure 1. Images of the biomass in control and CF reactors: (a) day 10 and (b) day 135. The size bar is $2 \mathrm{~mm}$. 
(a1)

Control

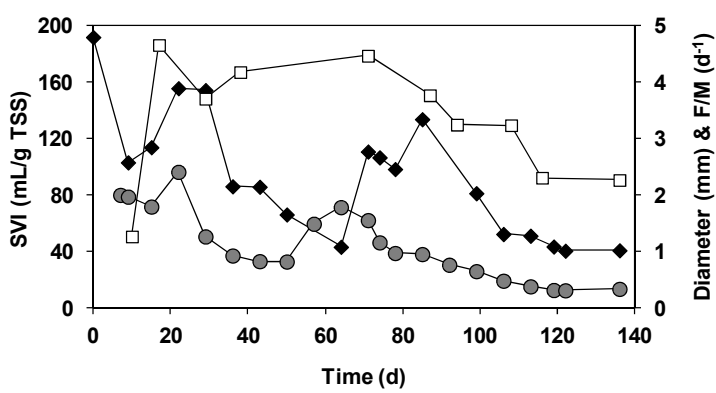

(b1)

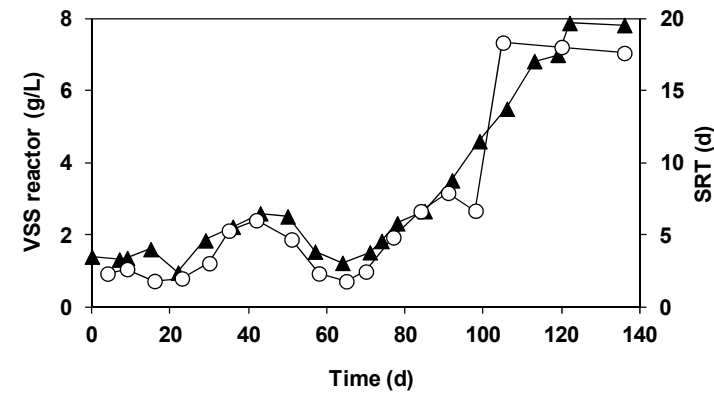

(a2)

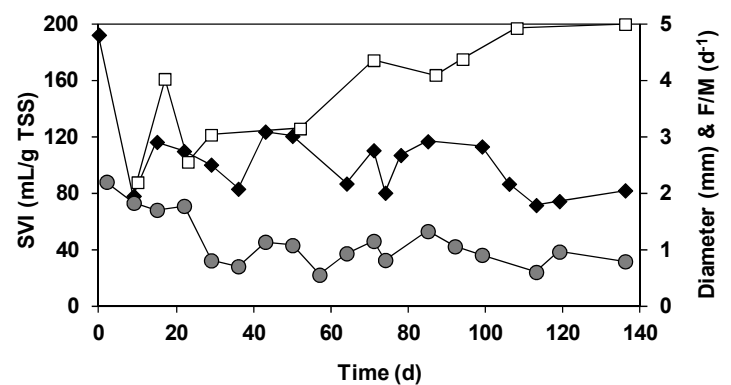

(b2)

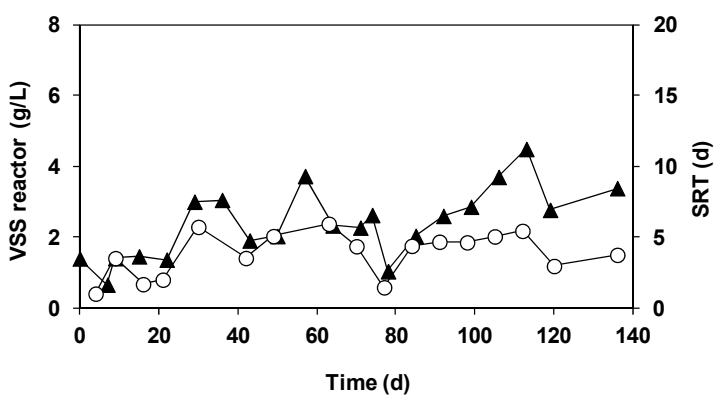

Figure 2. Biomass characteristics in control and CF reactors: (a) ( $\bullet$ ) biomass SVI, ( $\square$ ) granules diameter and $(\bullet)$ F/M ratio; (b) ( $\Delta$ ) VSS concentration in the reactor and (o) SRT. 
(a)

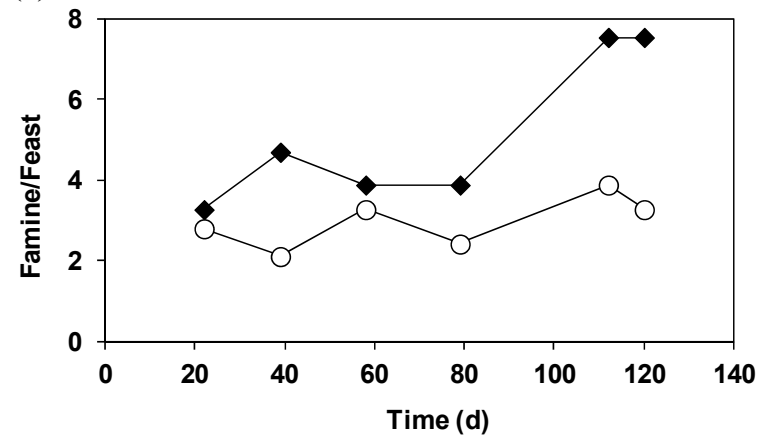

(b)

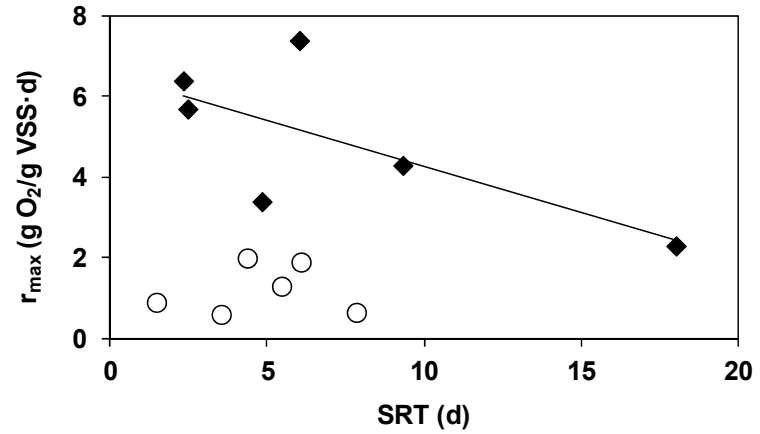

Figure 3. (a) Famine/Feast ratio during the operational period and (b) Maximum specific oxygen consumption rate $\left(\mathrm{r}_{\max }\right)$ at different SRT values: Control $(\diamond)$ and CF reactor $(\circ)$. 
(a)

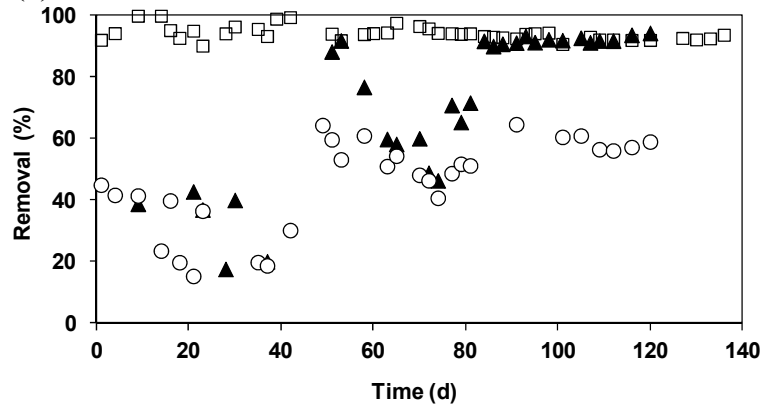

(b)

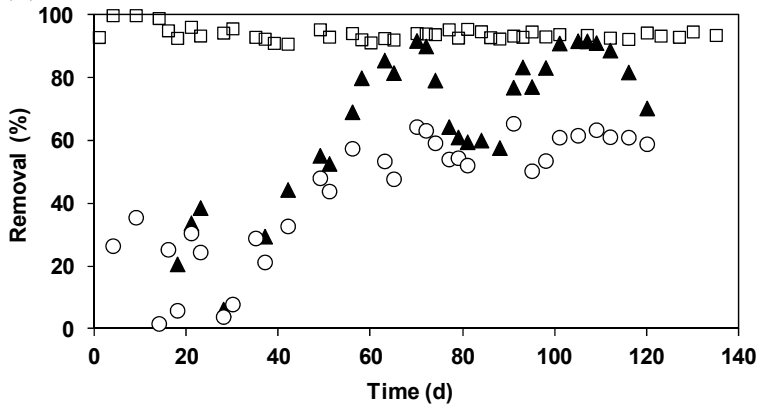

Figure 4. Percentage of $\mathrm{COD}_{\mathrm{S}}$ removal ( $\square$ ), $\mathrm{NH}_{4}{ }^{+}$oxidation $(\boldsymbol{\Delta})$ and $\mathrm{TN}$ removal (O) in (a) control and (b) CF reactor. 
(a)

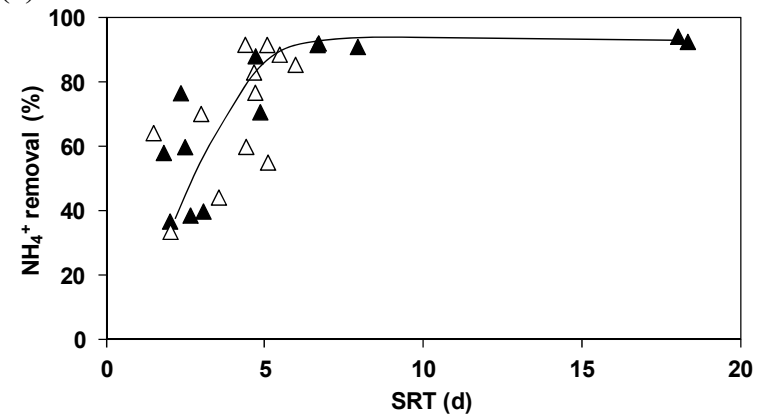

(b)

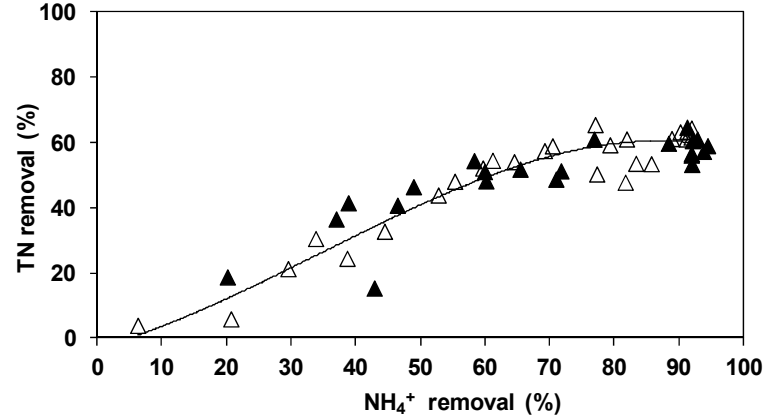

Figure 5. (a) Percentage of $\mathrm{NH}_{4}^{+}$oxidation as a function of the SRT and (b)

Relationship between $\mathrm{TN}$ and $\mathrm{NH}_{4}{ }^{+}$removal percentages in control $(\boldsymbol{\Delta})$ and $\mathrm{CF}(\triangle)$. 